\title{
Editorial
}

\section{Má conduta nas publicações científicas: precisamos falar sobre isso!}

Misconduct in scientific publications: we need to talk about it!

Mala conducta em publicaciones científicas: ¡tenemos que hablar de eso!

A epidemia de coronavírus trouxe inúmeras consequências, entre elas a retomada da discussão sobre más práticas no meio acadêmico-científico. As revistas The Lancet (1) e New England Journal of Medicine (2) protagonizaram, recentemente, casos de retratação de artigos sobre covid-19, cujas fontes de dados primárias utilizadas nas pesquisas não apresentaram o grau de confiabilidade compatível com as exigências científicas.

Embora a má conduta não seja um conceito fechado, pois à medida que os métodos científicos evoluem novas práticas podem ser incluídas, no geral se referem a plágio, conflito de interesses, falsificação e/ou fabricação de dados e maus tratos aos sujeitos de pesquisa (3).

Casos de fraudes, plágios e autoplágios são cada vez mais perceptíveis e isso se deve especialmente ao advento das publicações eletrônicas, que permite, além da rápida disseminação do conhecimento, o controle externo feito pela própria comunidade científica. Contudo, podem gerar consequências perversas como a queda da fiabilidade do conhecimento científico que é corretamente produzido e divulgado, impactando diretamente no avanço da ciência. No panorama atual em que se combatem as fake news, é importante que a ciência seja o contraponto, e casos de plágio, falsificação de dados ou ainda a sua fabricação, acabam por ferir esse processo de confiança.

Por outro lado, a ampla divulgação de episódios de má prática também tem o condão de desestimular essas ações, tanto pela dimensão punitiva, em que o autor da fraude pode sofrer processos - cíveis, criminais e administrativos - e, com isso, ter sanções que podem ir desde o pagamento de indenizações, multa, devolução de recursos de pesquisa à privação de liberdade em casos extremos; como pela dimensão pedagógica, em que a divulgação serve para desestimular novas fraudes do autor no futuro, ou de outros indivíduos que estejam pensando em praticar tal conduta. Ou seja, a divulgação dos casos identificados serve para demonstrar que o fraudador sofrerá consequências rigorosas, inclusive abalo na sua credibilidade científica. (4) 
Necessário ainda estimular reflexões mais perenes na academia, envolvendo pesquisadores, professores e alunos, acerca da responsabilidade e ética na ciência. O excesso de produtivismo, que tanto se debate, não pode ser usado como escusa para esse tipo de ação.

No campo da comunicação científica, um conjunto de atores é responsável pela validação do conhecimento produzido, sendo o parecerista o pilar principal nesse processo de identificação de práticas fraudulentas. Todavia, o aumento no volume de manuscritos submetidos tem tornado essa tarefa mais difícil, fazendo com que a perquirição de fraudes nem sempre seja feita de forma aprofundada. Por outro lado, os softwares de identificação de plágio, ferramenta comumente utilizada em diversos periódicos, não solucionam o problema como um todo, vez que identificam similaridades no texto, precisando ainda de um processo de revisão do editor para verificar se essas similaridades se constituem efetivamente em práticas fraudulentas.

O Cadernos Ibero-Americanos de Direito Sanitário (CIADS), em sua prática editorial, se apoia nas diretrizes estabelecidas pelo Committee on Publication Ethics (COPE) (5) - que orientam os membros da cadeia de editoração na busca pelas melhores práticas de publicação acadêmica - e conta com revisores comprometidos eticamente com o seu papel, razão pela qual rende sinceros agradecimentos a esses firmes apoiadores.

Inexiste uma solução mágica e infalível para o tema da má conduta nas publicações científicas, mas é importante combatê-la incansavelmente, de modo que se torne cada vez mais desvantajoso correr o risco de enveredar por caminhos obtusos, sejam lá quais forem as desculpas utilizadas para tal. Defender um compromisso ético e responsável pelo bem da ciência é papel de toda a comunidade acadêmica e científica.

Sandra Mara Campos Alves Maria Célia Delduque

Editoras científicas

Cadernos Ibero-Americanos de Direito Sanitário (CIADS)

\section{Referências}

1. Mehra MR, Desai SS, Ruschitzka F, Patel AN. Retraction -Hydroxychloroquine or chloroquine with or without a macrolide for treatment of COVID-19: a multinational registry 
analysis. Lancet. 2020; (published online May 22.) Disponível em:

https://www.thelancet.com/journals/lancet/article/PIIS0140-6736(20)31324-

6/fulltext\#seccestitle10 [Acesso em 5 de jun 2020].

2. Mehra MR, Desai SS, Kuy S, Henry TD, Patel AN. Retraction: Cardiovascular disease, drug therapy, and mortality in Covid-19. N Engl J Med. DOI: 10.1056/NEJMoa2007621. Disponível em: https://www.nejm.org/doi/full/10.1056/NEJMc2021225\#article_citing_articles [Acesso em: 5 de jun 2020].

3. Scott-Lichter D, Editorial Policy Committee, Council of Science Editors. Diretrizes do CSE para Promover Integridade em Publicações de Periódicos Científicos, Atualização de 2012. 1 ed. Associação Brasileira de Editores Científicos, Botucatu, SP, 2017. Disponível em: https://www.abecbrasil.org.br/arquivos/whitepaper_CSE.pdf [Acesso em 1 de jun 2020].

4. Michalek AM, Hutson AD, Wicher CP, Trump DL. The Costs and Underappreciated Consequences of Research Misconduct: A Case Study. PLoS Med 7(8): e1000318. doi:10.1371/journal. pmed.1000318. Disponível em:

https://www.ncbi.nlm.nih.gov/pmc/articles/PMC2923086/ [Acesso em: 1 de jun 2020].

5. Committee on Publication Ethics. Core practices. Disponível em: https://publicationethics.org/core-practices [Acesso em 1 de jun 2020].

Alves SMC, Delduque MC. Má conduta nas publicações científicas: precisamos falar sobre isso!. Cadernos IberoAmericanos de Direito Sanitário. 2020 abr./jun.; 9(2): 09-11. 